\title{
Vitamin E supplementation, cereal feed type and consumer sensory perceptions of poultry meat quality
}

\author{
Orla B Kennedy, Barbara J Stewart-Knox*, Peter C Mitchell and David I Thurnham \\ Northern Ireland Centre for Food and Health (NICHE), School of Biomedical Sciences, University of Ulster, Coleraine, Northern Ireland \\ (Received 20 December 2003 - Revised 21 October 2004 - Accepted 25 October 2004)
}

\begin{abstract}
Lipid oxidation leads to meat spoilage and has been reported to cause adverse changes in the flavour and texture of poultry meat. Vitamin E has been found to be effective in delaying lipid oxidation. The aim of this study was to determine whether the vitamin E supplementation of chicken feed influences the consumers' perception of the quality of chicken meat under normal display and storage conditions. Untrained consumers ( $n$ 32) evaluated cooked breast meat from chickens (both corn fed and wheat fed) supplemented with 75250 or $500 \mathrm{mg} / \mathrm{kg}$ vitamin E and after storage at $4{ }^{\circ} \mathrm{C}$ for 4 and $7 \mathrm{~d}$. Factorial analysis found an interaction between vitamin $\mathrm{E}$ treatment and storage day upon the perceived juiciness $(P=0 \cdot 023)$ and tenderness $(P=0 \cdot 041)$ of the chicken meat. Perceptions of quality relative to vitamin E level were more evident on day 4 than day 7 . When the two cereal types were compared, the time-related subgroup effects were observed only in meat from corn-fed chickens supplemented with either 75 or $250 \mathrm{mg} / \mathrm{kg}$, which was perceived to be juicier $(P=0 \cdot 018)$ and more tender $(P=0.020)$ than that supplemented at the $500 \mathrm{mg} / \mathrm{kg}$ level. These results imply that the two lower concentrations of vitamin E have some advantages over $500 \mathrm{mg} / \mathrm{kg}$, but for optimal consumer acceptance of corn-fed chicken meat, we suggest that $250 \mathrm{mg} / \mathrm{kg}$ vitamin $\mathrm{E}$ should be added to cornfed poultry feed. There was no evidence to suggest any advantages in changing the current amount of vitamin $\mathrm{E}$ ( $75 \mathrm{mg} / \mathrm{kg}$ ) used to rear wheat-fed birds.
\end{abstract}

Consumer: Sensory evaluation: Poultry meat quality: Vitamin E

Lipid oxidation has been associated with adverse changes in the appearance, flavour and texture of poultry meat (Jensen et al. $1998 b$ ). Flesh discoloration, increased drip loss and the development of 'off-odours' and 'off-flavours' in meats are indicative of a lack of freshness (Gray et al. 1996). Apart from microbial spoilage, lipid oxidation is considered the primary mechanism causing the deterioration of quality in meat products (Buckley et al.1995; Sarraga \& Garcia Regueiro, 1999), causing off-flavours or rancidity (Gray et al. 1996). Different nutritional strategies have been explored in an attempt to delay the onset of lipid oxidation and improve the quality of poultry meat. These have included varying the feed in terms of the fat content, fat source and cereal type, as well as the addition of antioxidants such as vitamin $\mathrm{C}$, carotenoids, tea catechins and vitamin E (Lin et al. 1989; Sheehy et al. 1993; Lauridsen et al. 1997; Jensen et al. 1998a; Bou et al. 2001; Tang et al. 2002). Supplementing chicken feed with vitamin $\mathrm{E}$ has been found to be protective against lipid oxidation in poultry meat detectable by either chemical indices or trained panellists (Jensen et al. 1998a). Few studies to date appear to have investigated the influence of chicken feed modifications upon consumer perceptions of poultry meat quality.

Studies that have carried out sensory evaluation have mainly looked at off-odour and off-flavour formation in response to vitamin E supplementation (Blum et al. 1992; Dewinne \& Dirinck, 1996; O'Neill et al. 1998) while neglecting quality parameters that consumers perceive to be important for product acceptance. Preliminary research carried out by our group indicated that consumers defined poultry meat quality in terms of 'tenderness', 'juiciness' and 'freshness' (Kennedy et al. 2002). The present study therefore explored these quality perceptions in addition to perceptions of flavour, appearance and liking in response to vitamin E feed supplements.

Previous studies investigating poultry meat quality have tended to use 'expert' or trained panels (Blum et al. 1992; O'Neill et al. 1998). It has been argued, however, that, by the nature of their training, expert panels are unsuitable where commercially relevant judgements are sought (McEwan, 1997). Untrained consumers were therefore used to make product assessments for the purpose of the present study. Furthermore, much previously published work has concentrated upon the effect of vitamin $\mathrm{E}$ on 'dark' meat from chicken legs and thighs, or minced meat patties from breast, thigh or mixed sources (Blum et al. 1992; O'Neill et al. 1998; Bou et al. 2001; Ruiz et al. 2001). Existing consumer research indicates that $76 \%$ of poultry meat sales are for whole or portioned products (Mintel, 2002). This research therefore assessed the effects of vitamin $\mathrm{E}$ on perceptions of chicken breast meat.

The present study is also unique in that it compared evaluations of breast meat derived from two differently pigmented chicken meats (corn and wheat fed). Preliminary research indicated that the yellow flesh colour of corn-fed chicken meat can impact negatively upon consumer perceptions of the flavour and texture of the product (Kennedy et al. 2004). Sensory assessments were therefore made under controlled lighting conditions to mask differences in product appearance. The purpose of this study was to investigate the impact of vitamin E supplementation at 75250 
or $500 \mathrm{mg} / \mathrm{kg}$ given to corn- and wheat-fed birds on consumer perceptions of chicken breast meat quality following storage for 4 and $7 \mathrm{~d}$ after slaughter.

\section{Methods}

\section{Chickens}

Day-old Ross broiler chicks (Carnview Hatcheries, Ballymena, Northern Ireland) from the same parent stock were assigned to one of six treatment groups and placed into pens with a stocking density of $34 \mathrm{~kg} / \mathrm{m}^{2}$ and a $23 \mathrm{~h}$ light, $1 \mathrm{~h}$ dark cycle, in accordance with the recommendations of the United Kingdom 'Quality Assured' chicken scheme (Assured Chicken Production, 2003).

\section{Feeding trials}

Chicks were fed ad libitum on either corn-based or wheat-based commercial proprietary feeds (starter, grower (Table 1), finisher, withdrawal), which were supplemented to provide either 75250 or $500 \mathrm{mg}$ vitamin E/ $\mathrm{kg}$ feed. The chickens had free access to water. Chicks were weighed (group-wise) at weekly intervals, at which times group feed intake, litter quality and mortality rates were recorded.

\section{Poultry processing}

Feed was withdrawn overnight prior to day 42 , when broilers were transported to a commercial processing plant where they were gas-stunned, ensanguined and eviscerated. At day 0 (kill day), following commercial processing of the chickens, whole chicken carcasses were hand-tied, packed, air-chilled and labelled according to treatment group.

\section{Sample selection and storage}

Broiler chickens from the eviscerated weight range $1.0-1.8 \mathrm{~kg}$ were selected from each of the six groups according to an automated weight-sorting commercial system (Automated Quality Assessment Centre; Stork PMT BV, Boxmeer, The Netherlands). Following overnight storage at $2^{\circ} \mathrm{C}$, chickens were transferred to storage at $-30^{\circ} \mathrm{C}$ until required for analysis. Prior to sensory

Table 1. Average feed composition of the basal grower diet for the corn- and wheat-based diets

\begin{tabular}{lcc}
\hline Grower feed & Corn fed $(\%)$ & Wheat fed† (\%) \\
\hline Wheat & 10.47 & $57 \cdot 27$ \\
Maize & 50.00 & 0 \\
Biscuit meal & 2.50 & 3.50 \\
Extrupro & 0 & 3.97 \\
Soya & 30.98 & $28 \cdot 10$ \\
Sunflower extracts & 0.93 & 2.50 \\
Calcium hydroxide & 0.88 & 0.84 \\
Dicalcium phosphate & 1.06 & 1.00 \\
Sodium carbonate & 0.07 & 0.07 \\
Sodium chloride & 0.12 & 0.12 \\
L-Lysine & 0.28 & 0.18 \\
Liquid methionine & 0.21 & 0.20 \\
Blended oils & 2.50 & 2.25 \\
\hline & \\
\hline
\end{tabular}

evaluation, chickens were thawed at $4^{\circ} \mathrm{C}$ for $24 \mathrm{~h}$ and subsequently stored at this temperature for 3 and $6 \mathrm{~d}$ to represent day 4 and day 7 storage days.

\section{Outcome measures}

Overall product preference was assessed using the nine-point Hedonic Scale (Peryam \& Girardot, 1952). Evaluations of flavour, texture, juiciness, appearance and freshness were made using $10 \mathrm{~cm}$ visual analogue attribute scales employing terminology derived from previously published consumer studies (Munoz, 1998) and as suggested by preliminary qualitative research (Kennedy et al. 2004). Scales were anchored at each end with the following sensory descriptive terms: flavour (bland - very chickeny), juiciness (very dry - very moist), texture (very tough/chewy - very tender/soft), appearance (not very appealing - very appealing), freshness (not very fresh - extremely fresh). A $10 \mathrm{~cm}$ satiety rating scale was also included. Demographic information and information on meat consumption patterns were gathered prior to testing.

\section{Panel recruitment}

Panellists ( $n$ 32) were recruited from among University of Ulster employees by means of poster advertisement, email communication and personal contact. Those volunteers who consumed chicken at least once a month were recruited. This resulted in a convenience sample that included all categories of staff. The sample was stratified by the National Statistics Socio-Economic Classification Standard Occupational Classification (2002).

\section{Product preparation}

Chickens were weighed, wrapped in aluminium tin foil and placed breast side up in Pyrex roasting dishes. Products were cooked for $2 \mathrm{~h}$ at $200^{\circ} \mathrm{C}$ using a fan-assisted oven (Tricity Bendix Cook Centre S1510; Electrolux PLC, Luton, Bedfordshire, UK). the Pyrex dishes were rotated every $40 \mathrm{~min}$ to avoid any effect of oven position. The final cook temperature of the chickens was measured at the left thigh and breast positions using a handheld electronic thermometer (KM21 Food Check Thermometer; Comark Ltd, Stevenage Hertfordshire, UK) to ensure that a minimum internal temperature of $80^{\circ} \mathrm{C}$ had been reached. The chickens were drained of juices and the final cooked weight assessed. The left and right breasts were removed from the chicken carcasses, portioned for panels, covered in aluminium foil and held on a bain marie at a temperature of approximately $70^{\circ} \mathrm{C}$ prior to being served to consumers.

\section{Sensory evaluation}

Assessments took place in a purpose-built, four-booth sensory evaluation laboratory and were held during both morning and afternoon to minimise any diurnal effects upon judgements. Consumers attended a total of four panels, at each of which they were required to evaluate a total of six chicken products. Yellow filtered lighting was used to mask the differences in product pigment. Hot samples (approximately $20 \mathrm{~g}$ pieces) from the same locations on each breast type, for example, cranial (anterior/ wing position) or caudal (posterior/thigh position) position, were used for sensory evaluation. Samples were coded using random three-digit numbers and served singly, with the order of presentation counterbalanced. Products were evaluated in terms 
of flavour, juiciness, texture, appearance, freshness and overall liking using the scales described earlier. After evaluating each sample, participants were required to press a buzzer so that the sample could be removed prior to the participant being presented with subsequent samples. Panellists were instructed to rinse and swallow still bottled mineral water between samples. All participants received confectionery upon completion of the taste panels.

\section{Data analysis}

Visual analogue scale ratings (in $\mathrm{cm}$ ) and the hedonic liking scores were allocated to the appropriate product following decoding of the sample numbers. Statistical Packages for the Social Sciences (Version 11 SPSS UK; Ekrath, Germany) was used to analyse the responses across the product conditions.

A $3 \times 2 \times 2$ factorial design was used in this study. The variables investigated were vitamin $\mathrm{E}$ (three levels - 75250 and $500 \mathrm{mg} / \mathrm{kg}$ feed), cereal type (two levels - corn- and wheatbased feeds) and storage days (two levels - day 4 and day 7). Multivariate ANOVA was used to determine the effect of the different factors upon attribute and hedonic judgements with post-hoc analysis using Fischer's least significant difference. A $3 \times 2$ multivariate ANOVA was used to examine the effect of vitamin $\mathrm{E}$ supplementation (three levels) for each of the cereal types (corn and wheat) and storage day with post-hoc analysis using Fischer's least significant difference.

\section{Results}

\section{Farm feeding trial mortality outcomes}

The corn-fed chickens had significantly lower mortality rates than the wheat-fed chickens $\left(\chi^{2}=9.52 ; P<0.01\right)$. The $250 \mathrm{mg} / \mathrm{kg}$ level of vitamin $\mathrm{E}$ in the wheat-fed boilers was associated with a higher mortality rate than either the $75 \mathrm{mg} / \mathrm{kg}\left(\chi^{2}=6.88 ; P<0.01\right)$ or the $500 \mathrm{mg} / \mathrm{kg}\left(\chi^{2}=4.40 ; P<0.01\right)$ supplementation level. In cornfed chickens, no differences were observed in mortality between the three different supplementation levels (Table 2).

\section{Test consumer panel}

A total of eighteen females and fourteen males took part in the study, $84 \%(27 / 32)$ of whom were under 34 years of age. The sample was spread more or less equally across socio-economic groups 1·2, 2, 3 and students. The panellists' average consumption of chicken was two or three times per week.

\section{Vitamin E and storage day}

The main $3 \times 2 \times 2$ factorial multivariate ANOVA indicated that differences between the vitamin $\mathrm{E}$ treatments influenced consumers' appreciation of juiciness and tenderness of chicken meat $(P<0 \cdot 1)$, but both effects were dependent upon time of storage before use $(P<0.05$; Table 3$)$. Post-hoc analysis of the different vitamin $\mathrm{E}$ treatments and storage times indicated that the meat from chickens supplemented with the $250 \mathrm{mg} / \mathrm{kg}$ level of vitamin $\mathrm{E}$ was perceived to be more juicy than that supplemented at either the 75 or $500 \mathrm{mg} / \mathrm{kg}$ levels $(P<0.05)$ and more juicy after storage for $4 \mathrm{~d}$ than $7(P=0.022)$. In addition, texture ratings suggested that meat supplemented with the 75 and $250 \mathrm{mg} / \mathrm{kg}$ levels of vitamin $\mathrm{E}(P=0.050$ and $P=0.037$ respectively) was perceived to be more tender than that supplemented at the $500 \mathrm{mg} / \mathrm{kg}$ level. Furthermore, meat supplemented with the $250 \mathrm{mg} / \mathrm{kg}$ level of vitamin $\mathrm{E}$ was perceived more favourably in terms of flavour $(P=0.025)$, juiciness $(P=0.022)$, freshness $(P=0.029)$ and liking $(P=0.031)$ at day 4 than day 7 (Table 4 ). The only feature that was rated more highly for meat stored for 7 than $4 \mathrm{~d}$ was the texture of meat from the $500 \mathrm{mg} / \mathrm{kg}$ treatment group $(P=0.028$; Table 4$)$.

\section{Cereal type, vitamin $E$ and storage day}

Cereal feed type in the initial analysis did not appear to influence quality perceptions independently of vitamin E level or storage day (Table 3). Since one of the aims of the study was, however, to investigate the effects of vitamin $\mathrm{E}$ on different cereal types, post-hoc analyses were carried out to investigate which meats

Table 2. Mean final live weights, feed conversion ratios and mortality rates according to vitamin E supplementation level and broiler feed type

\begin{tabular}{|c|c|c|c|c|c|c|}
\hline \multirow[b]{2}{*}{ Vitamin E level } & \multicolumn{2}{|c|}{$75 \mathrm{mg} / \mathrm{kg}$} & \multicolumn{2}{|c|}{$250 \mathrm{mg} / \mathrm{kg}$} & \multicolumn{2}{|c|}{$500 \mathrm{mg} / \mathrm{kg}$} \\
\hline & Corn (n 227) & Wheat ( $n$ 225) & Corn (n 227) & Wheat ( $n$ 213) & Corn (n 226) & Wheat ( $n$ 223) \\
\hline Average weight (g) & $207 \cdot 1$ & 2188.6 & $1938 \cdot 2$ & $2219 \cdot 0$ & $2121 \cdot 5$ & $2166 \cdot 4$ \\
\hline Feed conversion ratio & 1.85 & 1.88 & 1.92 & 1.89 & 1.82 & 1.87 \\
\hline Mortality (\%) & $1 \cdot 3$ & $2 \cdot 2$ & $1 \cdot 3$ & $7 \cdot 4$ & 1.7 & 3.0 \\
\hline
\end{tabular}

Table 3. Effect of vitamin E supplementation level, broiler feed type and storage days and their interactions on the mean sensory ratings for consumer-perceived quality of cooked chicken breasts

\begin{tabular}{lccccc}
\hline & Flavour & Juiciness & Texture & Appearance & Freshness \\
\hline Vitamin E & NS & $*$ & $*$ & NS & NS \\
Cereal type & NS & NS & NS & NS & NS \\
Storage day & NS & NS & NS & NS & NS \\
Vitamin E $\times$ cereal type & NS & NS & NS & NS & NS \\
Vitamin E $\times$ storage day & $*$ & $* *$ & NS \\
Cereal type $\times$ storage day & NS & NS & NS & NS & NS \\
Vitamin E $\times$ cereal type $\times$ storage day & NS & NS & NS & NS & NS \\
\hline
\end{tabular}

${ }^{\star} P<0 \cdot 1,{ }^{\star \star} P<0.05$ 
benefited most from the vitamin E supplements in terms of juiciness and texture (Table 5). The benefits of vitamin $\mathrm{E}$ were apparent only in meat from the corn-fed chicken and only on day 4. When the two cereal types were compared, vitamin $\mathrm{E}$ was found to enhance perceptions of juiciness $(P=0.018)$ and texture $(P=0.020)$ in meat from the corn-fed but not the wheat-fed chickens. On day 4, meat from corn-fed broilers supplemented with the 75 and $250 \mathrm{mg}$ levels of vitamin $\mathrm{E}$ was perceived to be juicier $(P=0.032$ and $P=0.007$ respectively) and more tender $(P=0.011$ and $P=0.024$ respectively) than that supplemented with $500 \mathrm{mg} / \mathrm{kg}$ vitamin E. Neither the vitamin E treatments nor the different storage times appeared to influence judgements of the wheat-fed chicken attributes.

\section{Discussion}

Factorial analysis of the data obtained in this study found that vitamin $\mathrm{E}$ treatment interacted with storage time in influencing consumer perceptions of juiciness and texture in chicken-breast meat. Sub-group analysis showed that: (1) the $250 \mathrm{mg} / \mathrm{kg}$ level of vitamin E supplementation was perceived to enhance the above qualities of meat better than either the $75 \mathrm{mg} / \mathrm{kg}$ or the $500 \mathrm{mg} / \mathrm{kg}$ level; (2) these qualities were perceived to be better on day 4 than day 7; (3) both the supplemental-level and storage-time effects were evident only in the corn-fed meat.

Previous studies have assessed chicken meat quality in response to vitamin $\mathrm{E}$ supplementation in relation to only one type of poultry cereal feed. The present study is different in comparing the effect of vitamin $\mathrm{E}$ in relation to both corn- and wheatbased feeds. In the initial analysis, there was no apparent difference between the two cereal types, and it was later sub-group analysis that showed that consumers rated meat from the cornfed birds as more juicy and tender than that obtained by feeding wheat. Our previous research indicated that variations in the pigment of poultry meat produced by the feed could influence consumer perceptions in other sensory modalities (Kennedy et al. 2004). Differences in the colour of the meat samples were therefore masked using filtered lighting. Consequently, no differences were observed across any of the conditions in terms of the appearance of the chicken meat. This indicates the effectiveness of using the filtered lighting to mask colour differences owing to product pigmentation or product discoloration that may have occurred over storage time. If appearance had been judged under natural light, previous research by the group (Kennedy et al. 2004) suggests that differences in the pigment of the poultry would have confounded any effects of vitamin E, cereal type or storage day upon consumer perceptions. This highlights the importance of controlling product appearance when oro-sensory assessments are being made.

There was no effect of vitamin E supplementation on consumer perception of wheat-fed chicken meat. This would indicate that vitamin E supplementation exerts a greater effect on corn-fed chicken meat than on wheat fed-chickens. The reason for the apparently greater susceptibility of gustatory properties of cornfed than wheat-fed chicken meat to be influenced by vitamin $\mathrm{E}$ treatment is not known. Further research in this area is needed. The company participating in this research used $75 \mathrm{mg} / \mathrm{kg}$ vitamin $\mathrm{E}$ as standard in its feed, and the results suggest that there is no advantage in increasing this for wheat-fed birds. The results of this study suggest that, for corn-fed birds, there may be some advantages in increasing the vitamin $\mathrm{E}$ supplement to $250 \mathrm{mg} / \mathrm{kg}$. 
Table 5. Mean (SD) sensory ratings for consumer-perceived quality of cooked chicken breasts prepared after chilled storage for 4 and 7 days according to vitamin E supplementation level and broiler feed type

\begin{tabular}{|c|c|c|c|c|c|c|c|c|c|c|c|c|c|}
\hline \multirow[b]{3}{*}{ Corn/wheat } & \multirow{3}{*}{$\begin{array}{c}\text { Vitamin } \mathrm{E} \\
\text { level }\end{array}$} & \multicolumn{6}{|c|}{ Juiciness* } & \multicolumn{6}{|c|}{ Texture* } \\
\hline & & \multicolumn{2}{|c|}{ Day 4} & \multicolumn{2}{|c|}{ Day 7} & \multicolumn{2}{|c|}{$\begin{array}{l}\text { Combined } \\
\text { days }\end{array}$} & \multicolumn{2}{|c|}{ Day 4} & \multicolumn{2}{|c|}{ Day 7} & \multicolumn{2}{|c|}{$\begin{array}{l}\text { Combined } \\
\text { days }\end{array}$} \\
\hline & & Mean & SD & Mean & SD & Mean & SD & Mean & SD & Mean & SD & Mean & SD \\
\hline \multirow[t]{3}{*}{ Corn fed } & 75 & $5 \cdot 66^{a, c}$ & 2.37 & $5 \cdot 33^{a, c}$ & $2 \cdot 20$ & $5 \cdot 50^{c}$ & $2 \cdot 27$ & $6 \cdot 12^{a, c}$ & $2 \cdot 38$ & $5.95^{a, c}$ & $2 \cdot 19$ & $6 \cdot 03^{c}$ & 2.27 \\
\hline & 250 & $6 \cdot 30^{a, c}$ & 2.56 & $5 \cdot 10^{a, c}$ & 2.42 & $5 \cdot 72^{c}$ & 2.55 & $6 \cdot 23^{a, c}$ & 2.35 & $5 \cdot 60^{a, c}$ & $2 \cdot 28$ & $5 \cdot 92^{c}$ & 2.32 \\
\hline & ANOVA $^{* *} P=$ & 0.001 & & 0.884 & & 0.018 & & 0.008 & & 0.648 & & 0.02 & \\
\hline \multirow[t]{4}{*}{ Wheat fed } & 75 & $4 \cdot 76^{a, c}$ & $2 \cdot 25$ & $5 \cdot 47^{\mathrm{a}, \mathrm{c}}$ & $2 \cdot 22$ & $5 \cdot 12^{c}$ & $2 \cdot 25$ & $5 \cdot 43^{a, c}$ & $2 \cdot 20$ & $6 \cdot 00^{a, c}$ & 1.83 & $5 \cdot 72^{c}$ & 2.03 \\
\hline & 250 & $5 \cdot 80^{a, c}$ & $2 \cdot 10$ & $5 \cdot 20^{a, c}$ & $2 \cdot 29$ & $5 \cdot 54^{\mathrm{C}}$ & $2 \cdot 20$ & $6 \cdot 12^{a, c}$ & $2 \cdot 12$ & $5 \cdot 67^{a, c}$ & $2 \cdot 15$ & $5 \cdot 90^{\mathrm{C}}$ & $2 \cdot 13$ \\
\hline & 500 & $5 \cdot 24^{a, c}$ & 2.45 & $5 \cdot 39^{a, c}$ & $2 \cdot .29$ & $5 \cdot 31^{\mathrm{c}}$ & 2.35 & $5 \cdot 32^{a, c}$ & $2 \cdot 13$ & $6 \cdot 02^{a, c}$ & 1.97 & $5 \cdot 67^{c}$ & 2.06 \\
\hline & ANOVA $P=$ & 0.149 & & 0.887 & & 0.575 & & 0.272 & & 0.733 & & 0.805 & \\
\hline
\end{tabular}

* Sensory rating measured on a $10 \mathrm{~cm}$ line scale.

a,b Mean values within the same rows with different superscript letters for the different quality attributes are significantly different, as determined by Fisher's least significant difference $(P<0.05)$.

${ }^{\mathrm{c}, \mathrm{d}}$ Mean values within the same columns with different superscript letters are significantly different, as determined by Fisher's least significant difference $(P<0.05)$.

${ }^{* *} \mathrm{P}$ values shown for ANOVA on specific day and treatment groups of data.

Lipid oxidation has been found to be associated with adverse changes in the appearance, flavour and texture of poultry meat, which it may be possible to offset by supplementing the feed with vitamin E. Vitamin E supplementation has been found to be protective against lipid oxidation in poultry meat (Jensen et al. 1998b). Several studies have demonstrated the effectiveness of supplemental vitamin $\mathrm{E}$ in reducing lipid oxidation, by measurement of thiobarbituric acid reactive substances and cholesterol oxidation products (Lin et al. 1989; Jakobsen et al. 1995; Jensen et al. 1995a,b; Galvin et al. 1998). Off-flavour, off-odour formation and warmed-over flavour in meat are associated with lipid oxidation. Previous studies, using trained panels, have shown that vitamin E supplementation can delay off-flavour formation as detected by sensory assessment (Dewinne \& Dirinck, 1996; Galvin et al. 1998; O'Neill et al. 1998; Bou et al. 2001), and off-flavour formation has been demonstrated to be highly correlated with chemical indices such as thiobarbituric acid reactive substances. Few studies to date appear to have investigated the influence of chicken feed modifications upon consumer perceptions of poultry meat quality. Our findings imply that vitamin $\mathrm{E}$ can bring about improvements in meat quality that are perceptible to untrained consumers.

It has been suggested that vitamin $\mathrm{E}$ supplementation decreases drip loss in meat and maintains water-holding capacity (Buckley et al. 1995), which is associated with increased meat tenderness (Warrwiss, 2000). An enhanced water-holding capacity has been attributed to the ability of vitamin $\mathrm{E}$ to maintain the integrity of the cell membrane, which protects the membranal lipids against lipid oxidation, thereby reducing drip loss (Asghar et al. 1991). In this study, increasing the feed vitamin $E$ content above the participating company's basal level of $75 \mathrm{mg} / \mathrm{kg}$ appears to benefit texture ratings up to, but not beyond, the $250 \mathrm{mg} / \mathrm{kg}$ supplementation level. This appears to contradict previous findings (Ruiz et al. 2001) that have not found any difference in the juiciness and tenderness of cooked leg meat from broilers fed either a control diet $(20 \mathrm{mg} / \mathrm{kg}$ vitamin E) or a diet supplemented with $200 \mathrm{mg}$ vitamin $\mathrm{E} / \mathrm{kg}$ feed. Differences in study design probably explain the difference in results. Previous studies used chicken leg rather than breast meat. Leg meat undergoes lipid oxidation at a faster rate than breast meat (Tang et al. 2002); thus, vitamin $\mathrm{E}$ supplementation may afford greater protection to leg meat than breast meat.

Consumers in the present study were unable to detect any differences in flavour as a result of vitamin E supplementation, although they did find the flavour better on day 4 than day 7 in the $250 \mathrm{mg} /$ $\mathrm{kg}$ treatment group. Previous research assessing meat quality in response to vitamin $\mathrm{E}$ supplementation has tended to use trained panellists. As the panellists in the present study were untrained, it would have been inappropriate to ask them to assess off-flavours, such as warmed-over flavour, as measured in other studies, as they would be unfamiliar with this concept. Dewinne \& Dirinck (1996) showed that untrained panels were less able to detect offflavour in chicken supplemented with $200 \mathrm{mg} / \mathrm{kg}$ vitamin $\mathrm{E}$ for up to $6 \mathrm{~d}$ compared with a basal feed. The panellists in this study, in contrast, were required to assess flavour quality using terminology meaningful to them.

It is again possible that apparent differences between these and prior findings in relation to flavour ratings in response to vitamin E could be in part because previous studies have evaluated responses in leg meat and not breast meat as used in this study. It is possible that if dark (leg) meat had been evaluated, consumers might have been able to perceive more of a difference in flavour due to vitamin E supplementation. Since the aim of the present study was to investigate the effect of vitamin E supplementation on consumer assessments of the most commercially important portion of chicken (breast meat), leg meat was not evaluated. It would be useful for future research to consider differences in sensory assessments across different cuts of meat.

There is considerable debate over specifically what level of vitamin E supplementation is optimal for poultry meat quality. Recommendations range from $200 \mathrm{mg} / \mathrm{kg}$ (O'Neill et al. 1998) to $225 \mathrm{mg} / \mathrm{kg}$ (Bou et al. 2001) up to $400 \mathrm{mg} / \mathrm{kg}$ (Galvin et al. 1998) for the control of off-flavour. The studies upon which these recommendations are based have, however, used trained panellists and have again exclusively assessed dark chicken meat. This study, which, in seeking to reflect commercial conditions, has employed untrained panellists to evaluate chicken breast meat, suggests that vitamin E, irrespective of supplementation level, does not result in any perceptible difference in meat flavour. 
Given previous research indicating that vitamin E supplementation delays lipid oxidation and extends shelf-life, it was surprising to find that the benefits of vitamin $\mathrm{E}$ on poultry meat quality were perceived only on day 4 and only at levels of $250 \mathrm{mg} / \mathrm{kg}$ or less. On day 4, corn-fed chicken meat supplemented at the $250 \mathrm{mg} / \mathrm{kg}$ level was judged to be juicier and more tender than that which was supplemented at either the $75 \mathrm{mg} / \mathrm{kg}$ or $500 \mathrm{mg} /$ $\mathrm{kg}$ level of vitamin E. In general, meat supplemented with $250 \mathrm{mg} / \mathrm{kg}$ of vitamin E was also perceived to be fresher and was liked more than that supplemented with either the 75 or the $500 \mathrm{mg} / \mathrm{kg}$ level. It would appear that the $500 \mathrm{mg} / \mathrm{kg}$ vitamin E level did not enhance the overall perceived quality of the cooked chicken meat and that the $250 \mathrm{mg} / \mathrm{kg}$ level was optimal in terms of both consumer-perceived texture quality and juiciness, although perceived differences were not detectable beyond $4 \mathrm{~d}$.

\section{Conclusion}

In conclusion, the results indicate that supplementation beyond the participating company's current commercial practice of $75 \mathrm{mg} / \mathrm{kg}$ is not warranted for chickens fed wheat-based feeds, but for corn-fed chicken, there may be gustatory advantages in using $250 \mathrm{mg} / \mathrm{kg}$ vitamin E.

\section{Acknowledgements}

The authors thank FarmFed Chickens Ltd, Coleraine, Northern Ireland and the Department of Education and Learning, Northern Ireland for their support in this project. Neither of the sponsors took any part in writing this report.

\section{References}

Asghar A, Gray JI, Booren AM, Gomaa EA, Abouzied MM \& Miller ER (1991) Effects of supranutritional dietary vitamin E levels on subcellular deposition of alpha-tocopherol in the muscle and on pork quality. J Sci Food Agric 57, 31-41.

Assured Chicken Production (2003) Poultry Standards 2003/2004. Available online www.assuredchicken.org.uk.

Blum JC, Touraille C, Salichon MR, Ricard FH \& Frigg M (1992) Effect of dietary vitamin-E supplies in broilers. 2. Male and female growthrate, viability, immune-response, fat-content and meat flavor variations during storage. Archiv Fur Geflugelkunde 56, 37-42.

Bou R, Guardiola F, Grau A, Grimpa S, Manich A, Barroeta A \& Codony RF (2001) Influence of dietary fat source, alpha-tocopherol, and ascorbic acid supplementation on sensory quality of dark chicken meat. Poultry Sci 80, 800-807.

Buckley DJ, Morrissey PA \& Gray JI (1995) Influence of dietary vitamin E on the oxidative stability and quality of pigmeat. J Animal Sci $\mathbf{I}$, 3122-3130.

Dewinne A \& Dirinck P (1996) Studies on vitamin E and meat quality. 2. Effect of feeding high vitamin E levels on chicken meat quality. J Agric Food Chem 45, 1691-1696.

Galvin K, Morrissey PA \& Buckley DJ (1998) Effect of dietary [alpha]tocopherol supplementation and gamma-irradiation on [alpha]-tocopherol retention and lipid oxidation in cooked minced chicken. Food Chem 62, 185-190.
Gray JI, Gomaa EA \& Buckley DJ (1996) Oxidative quality and shelf life of meats. Meat Sci 43, s111-s123.

Jakobsen K, Engberg RM, Anderson JO, et al. (1995) Supplementation of broiler diets with all-rac- $\alpha$ - or a mixture of natural source of $R R R$ alpha-, gamma-delta-tocopherol acetate. 1. Effect on vitamin E status of broilers in vivo and at slaughter. Poultry Sci 74, 1984-1994.

Jensen C, Skibsted LH, Jakobsen K \& Bertelsen G (1995a) Supplementation of broiled diets with all-rac- $\alpha$ or a mixture of natural source $R R R$-alpha-, gamma-delta-tocopherol acetate. 2. Effect on the oxidative stability of raw and precooked broiler meat products. Poultry Sci 74, 2048-2056.

Jensen C, Skibsted LH, Jakobsen K \& Bertelsen G (1995b) Dietary vitamin $\mathrm{E}$ and the quality of precooked chicken meat. Meat Focus Int $\mathbf{4}$, 401-402.

Jensen S, Jensen C, Jakobsen K, Engberg RM, Andersen JO, Lauridsen C, Sørensen P, Skibsted LH \& Bertlesen G (1998a) Supplementation of broiler diets with retinol acetate, beta-carotene or canthaxanthin: effect on vitamin status and oxidative status of broilers in vivo and on meat stability. Acta Agric Scand Section A Animal Sci 48, 28-37.

Jensen C, Lauridsen C \& Bertelsen G (1998b) Dietary vitamin E: quality and storage a stability of pork and poultry. Trends Food Sci Technol $\mathbf{9}$, $62-72$.

Kennedy OB, Stewart-Knox BJ, Mitchell PC \& Thurnham DI (2002) Consumer choice of chicken. Proc Nutr Soc 61, 81A.

Kennedy OB, Stewart-Knox BJ, Mitchell PC \& Thurnham DI (2005) Colour affects consumer sensory perceptions of poultry. Appetite (In the press).

Lauridsen C, Jensen C, Jakobsen K, et al. (1997) The influence of vitamin $\mathrm{C}$ on the antioxidative status of chickens in vivo, at slaughter and on the oxidative stability of broiler meat products. Acta Agric Scand Section A Animal Sci 47, 187-196.

Lin CF, Gray A, Asghar A, Buckley DJ, Booren AM \& Fegal CJ (1989) Effects of dietary oils and a-tocopherol supplementation on lipid composition on stability of broiler meat. J Food Sci 54, 1457-1460.

McEwan JA (1997) A comparative study of three product acceptability trials. Food Qual Prefer 8, 183-190.

Mintel (2002) Poultry UK August 2002. London Mintel International Group Limited.

Munoz AM (1998) Consumer perceptions of meat. Understanding these results through descriptive analysis. Meat Sci 49, S287-S295.

National Statistics Socio-Economic Classification (2002) The National Statistics Socio-Economic Classification User Manual, Version 1, April 2002. London: Office for National Statistics/HMSO.

O’Neill LM, Galvin K, Morrissey PA \& Buckley DJ (1998) Comparison of effects of dietary olive oil, tallow and vitamin $\mathrm{E}$ on the quality of broiler meat and meat products. Br Poultry Sci 39, 365-371.

Peryam D \& Girardot NF (1952) Advanced taste test. Food Engin 24, $58-61$.

Ruiz JA, Guerrero L, Arnau J, Guardia MD \& Esteve-Garcia EL (2001) Descriptive sensory analysis of meat from broilers fed diets containing vitamin $\mathrm{E}$ or beta-carotene as antioxidants and different supplemental fats. Poultry Sci 80, 976-982.

Sarraga C \& Garcia Regueiro JA (1999) Membrane lipid oxidation and proteolytic activity in thigh muscles from boilers fed different diets. Meat Sci 52, 213-219.

Sheehy PJ, Morrissey PA \& Flynn A (1993) Influence of heated vegetable-oils and alpha-tocopheryl acetate supplementation on alpha-tocopherol, fatty-acids and lipid- peroxidation in chicken muscle. $\mathrm{Br}$ Poultry Sci 34, 367-381.

Tang SZ, Kerry JP, Sheehan D \& Buckley DJ (2002) Antioxidative mechanisms of tea catechins in chicken meat systems. Food Chem 76, $45-51$.

Warriss PD (2000) Meat Science: An Introductory Text. Wallingford: CABI Publishing. 